\title{
Occasíonal inotes.
}

\section{A REPORT ON THE THIRD GERMAN MEDIGAL CONGRESS FOR PSYGHOTHERAPY, BADEN-BADEN, 1928.}

\author{
By GEORGE GERO, VienNa.
}

IN Germany the interest in psychotherapy is continually increasing. Not only specialists who deal with the psychically suffering but also the general practitioner, the gynæcologist, the internist and the tuberculosis expert wish for enlightenment with regard to the problems and the techniquis of this new science and art. This desire can readily be understood, the fundamental issue of the psychotherapeutic movement being the idea that it is always man as an entity who is the object of the whole activity and thought of the physician, and that disease is frequently a compound of connected physical and psychical factors. That is why efforts are being made to elaborate, consciously and systematically, methods of psychical treatment which have always been intuitively used by the best physicians, and to elevate them to the rank of an important part of the general equipment of the modern medical man.

At this meeting, which was the third of its kind, many general practitioners were present who were looking out for information with regard to the results and the development of psychotherapy, and evidently found it. As a matter of course the paricipation of the specialists has been equally active, the aim of these meetings being a combined one. Primarily they act as an intermediary in delivering to the genera' practitioner a notion of the general problems of psychotherapy, but on the other hand (the dissension between the different schools representing strictly opposite opinions having become a rather radical one) they try to clear the way for a mutual understanding.

This time the two schools struggling for supremacy were the individual psychology of Dr. Alfred Adler and Freud's theory of psychoanalysis. Individual psychology was represented by the reports of Dr. Seif (Munich), Dr. Wexberg (Vienna), and Dr. Künkel (Berlin). Their psychoanalytical opponents were Dr. Schultz-Hencke (Berlin) and Professor Schilder (Vienna).

Dr. Seif gave an outline of the point of view of individual psychology with regard to the problem of neurosis. According to his explanations the neurosis is a social disturbance of interhuman relations, an excuse and an effort to justify the discouraged and egocentric individual in escaping from his life-work. Accordingly, the cure consists in educating the discouraged and dependent individual to become courageous and independent by converting his egocentric attitude into an appropriate one which makes him fit for life.

Dr. Wexberg reported on organ inferiority in connexion with certain results of internal medicine. According to his specifications Adler's doctrine of organ inferiority represents the extension of the principle of the point of minor resistance to the sphere of clinical pathology. Whilst the doctrine of constitution assumes partly the conception of a specific disposition for certain diseases, partly that of a constitutional debility of the whole organism, Adler asserts a predisposition of certain organs and organic systems for diseases of a different kind. There are families, for instance, with dispositional debility of the stomach-intestine system, which manifests itself in one case by an ulcus ventriculi, in another by gastric carcinoma, in a third case, it may be, by a dyspepsia. Dr. Wexberg is of opinion that this connexion is nowadays often accepted in constitutional research as well as in practical internal medicine. Less attention is paid to another section of Adler's doctrine, the compensation of organ inferiority. This super-compensation does not change an inferior organ into a normal one, but into an "emphasized" one. The psychologically important consequence of the compensation of an organ inferiority shows itself also in the fact that in the end the entire organism seems to be grouped round the "emphasizall organ" as its centre. 
Dr. Schultz-Hencke, one of the psychoanalytic speakers, declared all the theses of individual psychology to be implicitly contained in psychoanalysis, while the reverse is not the case. Individual psychology only inquires in what direction the symptoms are tending, whereas psychoanalysis also searches for the causes. He does not deny that individual psychology is performing satisfactory service in the range of what psychoanalysis calls " the secondary profit of disease," that is, demonstration of the actual psychical situation which favours the fixation of symptoms. But its range is far narrower, considering the enormous extension of the field, than that of psychoanalysis.

Professor Schilder analyzed Dr. Wexberg's report and gave a fundamental criticism of Alder's doctrine of organic inferiority. He pointed out that Adler's doctrine is, using a term of the modern psychology of form (Gestaltpsychologie), a typical piece-work (stückhaft). The inferior organ has no isolated place in the whole of the organism. How it may manifest itself depends on temperament, on strength of the affects and on the intellect of the entire personality. The problem of constitution reaches far too deep to be capable of being unlocked by the formula of organ inferiority.

The second subject of discussion was the problem of character. What is character, and how is it to be grasped? Professor Haeberlin (Basle), Dr. Allers (Vienna), and Dr. Klages (Zürich) tried to investigate these intricate problems.

Professor Haeberlin pointed out the tasks set for scientific characterology, and the means by which it is to solve them. The principal work of characterology is to constitute a psychologically and logically ordered system of the points in which two individual characters may differ. Characterological differences must follow the connexion of actions. This connexion is determined first by its form, and secondly by its content. Such formal characterological standpoints are, for instance, constancy of character, its differentiation, course of action, intelligence, memory, and so forth. The content is the interest manifesting itself through actions.

Dr. Allers, also, asserted that understanding of character must be based on the analysis of its actions. Every action tends towards a definite goal which always consists in establishing an entity. Besides, the action is in any case the settling of a tension out of which it has arisen, and which is cancelled through it. According to Dr. Allers character cannot be understood from the structure of impulses, nor does he acknowledge its being determined by innate moments of constitution. He defines character as the formal principle of the total of all reactions of a human being. Since action, being the architype of reaction, is directed towards values, character may be defined as the substance of individual laws of value-preference.

The third subject of the Congress was the relation between experimental psychology and psychotherapy. The lecturer, Professor Lewin (Berlin), pointed out in an extremely interesting paper that experimental psychology nowadays has become capable of treating successfully problems of emotional and impulsive life, i.e., of spheres of essential importance in therapy. It is by no means an essential quality of the experiment to keep apart from real life. In psychotherapeutic treatment everything depends on grasping the individual peculiarities of the case. In experimental psychology nowadays less stress is laid on the static procedure of research of laws, based on the experimental penetration of the dynamic structure of a relatively few concrete cases. Whether the experiment keeps nearer to or farther from real life does not depend upon its successful imitation of definite situations of life in its intensity, but on its establishing processes of action and the structure of systems, dynamically equivalent to the cases of everyday life in question. It is even possible to arrange situations within the field of laboratory-experimerıts wherein the person investigated is not aware of his being part of the experiment-experiments exempt from task. Dr. Lewin described experiments trying to explain tension and detension of need-systems, the degree of communication between different needs and psychical spheres, the question of repression, the different kinds of surrogate gratification, experiments which are already contributing by their essential results to throw light on these processes.

A series of lectures completed the programme. The lively debates after the lectures proved the active interest taken in these questions by the medical world, 